\title{
Corticosteroid Therapy for Severe Community-Acquired Pneumonia: A Meta-Analysis
}

\author{
Ming Cheng MD, Zhi-yong Pan MD, Jiong Yang PhD, and Ya-dong Gao PhD
}

\begin{abstract}
BACKGROUND: The debate about the efficacy of corticosteroids in the treatment of severe community-acquired pneumonia (CAP) is still a longstanding dilemma. We performed a meta-analysis including 4 randomized controlled trials (RCTs) to evaluate the effect of corticosteroids on the treatment of severe CAP in adults. METHODS: We performed a systematic review of published and unpublished clinical trials. Databases, including PubMed, Embase, CINAHL, and Cochrane (from their establishment to July 2013), were searched for relevant articles. Only RCTs of corticosteroids as adjunctive therapy in adult patients with severe CAP were selected. RESULTS: Four trials enrolling 264 patients with severe CAP were included. Use of corticosteroids significantly reduced hospital mortality compared with conventional therapy and placebo (Peto odds ratio $=0.39$, 95\% CI 0.17-0.90). The quality of the evidence underlying the pooled estimate of effect on hospital mortality was low, downgraded for inconsistency and imprecision. CONCLUSIONS: On the basis of the current limited evidence, we suggest that, although corticosteroid therapy may reduce mortality and improve the prognosis of adult patients with severe CAP, the results should be interpreted with caution due to the instability of pooled estimates. Reliable treatment recommendations will be raised only when large sufficiently powered multi-center RCTs are conducted. Key words: severe cap; corticosteroids; mortality; meta-analysis. [Respir Care 2014;59(4):557-563. ( 2014 Daedalus Enterprises]
\end{abstract}

\section{Introduction}

Community-acquired pneumonia (CAP) is the most common infectious respiratory disease. In developed countries, it is the leading cause of death from infection and the sixth most prevalent cause of overall mortality, thus contributing to high economic and social costs. ${ }^{1-3}$ Patients with severe CAP normally require mechanical ventilation (MV) and ICU admission. Despite remarkable advances in etiological investigation, antimicrobial therapy, and support-

Drs Cheng, Yang, and Gao are affiliated with the Department of Pneumology, and Dr Pang is affiliated with the Department of Neurosurgery, Zhongnan Hospital of Wuhan University, Wuhan, People's Republic of China.

The authors have disclosed no conflicts of interest.

Correspondence: Ya-dong Gao, PhD, Department of Pneumology, Zhongnan Hospital of Wuhan University, Donghu Road 169, Wuhan 430071, People's Republic of China. E-mail: gaoyadong@hotmail.com.

DOI: $10.4187 /$ respcare. 02758 ive measurements, the mortality of those patients still remains at $\sim 50 \% .4,5$ Therefore, additional potential approaches are needed for better outcomes in severe CAP.

Recent studies found that the levels of pro-inflammatory cytokines such as interleukin (IL)-6, IL-8, IL-10, IL$1 \beta$, tumor necrosis factor alpha, and interferon gamma were significantly increased in patients with severe CAP and correlated with the severities and outcomes of CAP. ${ }^{6-8}$ Appropriately producing cytokines in location play a role in inhibition and elimination of primary infection, but an excessive systemic and pulmonary inflammatory response in patients with severe CAP may contribute to injuries to the lung and other organs. This leads to sepsis, lung injury, and ARDS and is associated with poor prognosis and high mortality. ${ }^{8-11}$ Therefore, downregulation of systemic inflammatory response may improve the clinical course of severe CAP.

Corticosteroids are known to be the most potent inflammatory inhibitors. They inhibit expression of pro-inflammatory cytokines and accelerate expression of antiinflammatory cytokines. ${ }^{12}$ The immunomodulating and anti-inflammatory pharmacodynamic profile is the physi- 
ologic rationale for their use in patients with severe infection. Furthermore, as the conception of critical illnessrelated corticosteroid insufficiency was put forward, steroid replacement therapy has been gradually accepted as a treatment for patients with critical illnesses. ${ }^{13}$ By measuring random and cutoff levels of cortisol, Salluh et $\mathrm{al}^{14}$ found that patients with severe CAP had a high prevalence of adrenocortical insufficiency. Another study reported that the baseline cortisol levels were positively correlated with disease severity scores, for example, APACHE II (Acute Physiology and Chronic Health Evaluation II); Sequential Organ Failure Assessment; and confusion, urea nitrogen, breathing frequency, blood pressure, $\geq 65$ years of age (CURB-65). It has been suggested that baseline cortisol levels were better predictors of severity and outcome in patients with severe CAP than post-corticotropin cortisol levels or routinely measured laboratory parameters (Creactive protein, leukocyte count, and D-dimer) and scores of severity. ${ }^{15}$ Meduri et al ${ }^{16}$ demonstrated in an in vitro study that methylprednisolone (MPDN) could decrease lung inflammatory response and lung bacterial burden. Nevertheless, the notion that corticosteroid treatment is beneficial to severe CAP has not currently reached a consensus. Three retrospective trials ${ }^{17-19}$ and 2 randomized controlled trials (RCTs) ${ }^{20,21}$ demonstrated no improved outcomes (clinical cures or survival) for patients receiving corticosteroids as adjunctive therapy. Moreover, the results of a systematic review ${ }^{22}$ failed to confirm the effectiveness of corticosteroids in patients with severe CAP. In contrast, one meta-analysis ${ }^{23}$ investigated the outcome of the administration of corticosteroids, especially prolonged therapy, and found that corticosteroid treatment was associated with reduced mortality in a subgroup of patients with severe CAP. Four RCTs ${ }^{24-27}$ and one cohort study 28 concluded that corticosteroids combined with antibiotic therapy decreased mortality and improved outcomes of in-patients with severe CAP. Therefore, we conducted this meta-analysis to investigate the efficacy of corticosteroids in the management of severe CAP.

\section{Methods}

The study was performed at Zhongnan Hospital of Wuhan University, Wuhan, People's Republic of China.

\section{Search Strategy}

A literature search was performed independently by 2 investigators to identify RCTs from the following databases: PubMed, Embase, CINAHL, and Cochrane (from their inception to July 2013). The key words used were "severe CAP," "corticosteroids," "steroids," "methylprednisolone," and "hydrocortisone." We also reviewed the bibliographies and reference lists through a manual search

\section{QUICK LOOK}

\section{Current knowledge}

Community-acquired pneumonia (CAP) is the most common infectious respiratory disease. In developed countries, it is the leading cause of death from infection and the sixth most common cause of mortality. The role of corticosteroids in the treatment of CAP remains controversial.

\section{What this paper contributes to our knowledge}

Corticosteroid therapy appears to reduce mortality and to improve the prognosis of adults with CAP. The instability of pooled estimates suggests that treatment recommendations should await sufficiently powered multicenter randomized controlled trials.

of citations from retrieved articles to identify other potentially eligible studies.

\section{Selection Criteria}

For this meta-analysis, studies meeting the following criteria were included: (1) only studies designed as RCTs, (2) adult patients with severe CAP as participants, (3) intervention with corticosteroids used as adjunctive therapy for patients with severe CAP, (4) control intervention with placebo (normal saline solution or drugs with a physical appearance similar to corticosteroids), and (5) hospital mortality as the primary outcome. We excluded studies based on the following criteria: (1) studies enrolling pediatric patients or nosocomial pneumonia patients, (2) studies having only abstracts without full text, and (3) studies lacking adequate original data.

\section{Quality Assessment}

Two investigators assessed the eligibility and quality of selected studies blinded to each other and resolved any disagreement by consensus. We chose the Grading of Recommendations Assessment, Development, and Evaluation (GRADE) criteria to assess the quality of each randomized clinical trial. Following the GRADE recommendation, the classification of evidence quality consisted of high, moderate, low, and very low. The quality of RCTs was considered high, but it may be downgraded by the following factors: methods of randomization, allocation concealment, blinding, whether the analysis respected the intention-totreat principle, and whether trials avoided the risk associated with stopping for perceived benefit. 


\section{Corticosteroid Therapy for Severe Community-Acquired Pneumonia}

\section{Data Extraction}

Data extraction was performed independently by 2 investigators from each study, and relevant information consisted of the following: first author, year of publication, study design, number of patients, participant demographics, diagnostic criteria of severe CAP, corticosteroid treatment (drug, dose, and duration), and outcome variables. We contacted authors through e-mail to obtain key study details when needed. Any disagreements were resolved by iteration and consensus.

\section{Quantitative Data Synthesis}

Hospital mortality or, when that information was unavailable, mortality at the longest follow-up time was chosen as the primary end point. Secondary outcomes were length of hospital stay, length of ICU stay, duration of $\mathrm{MV}$, days off MV, and adverse effects. Those outcomes were analyzed on an intention-to-treat basis. We pooled study results of the common odds ratio (OR) and risk differences with a 95\% CI using a Peto model. ${ }^{29}$ Heterogeneity among studies was evaluated by Cochran's Q test and $\mathrm{I}^{2}$ statistics. If significant heterogeneity was shown $\left(P<.1, \mathrm{I}^{2}>50 \%\right)$, a random-effects model was selected; otherwise a fixed-effects model was used. Based on a Cochrane recommendation, heterogeneity was classified as low $(\leq 25 \%)$, moderate $(25-50 \%)$, and high $(>50 \%)$. We calculated the presence of publication bias using funnel plots. ${ }^{30}$ Statistical analysis was performed using the Review Manager 5.0 software (Cochrane Collaboration).

\section{Results}

\section{Trial Flow}

The literature search yielded 6,172 citations initially. We excluded 6,158 citations because they were duplications, the studies were not RCTs, or they were not related to CAP. After reviewing 14 full-text citations, 4 observational studies ${ }^{17-19,31}$ and one commentary ${ }^{32}$ were excluded. Thus, 9 RCTs about corticosteroid therapy for CAP met our inclusion criteria (Fig.1). We excluded 3 trials because they investigated patients with mild-to-severe CAP without classification. ${ }^{33-35}$ Another trial ${ }^{27}$ was excluded because it evaluated patients with a wide spectrum of severity (from classes I to V) but did not present mortality data in a subgroup of patients with severe CAP. At last, we decided to exclude the study by Marik et $\mathrm{al}^{20}$ from the analysis because its design was different from the other studies in that a single dose of corticosteroids prior to antibiotic therapy was used.

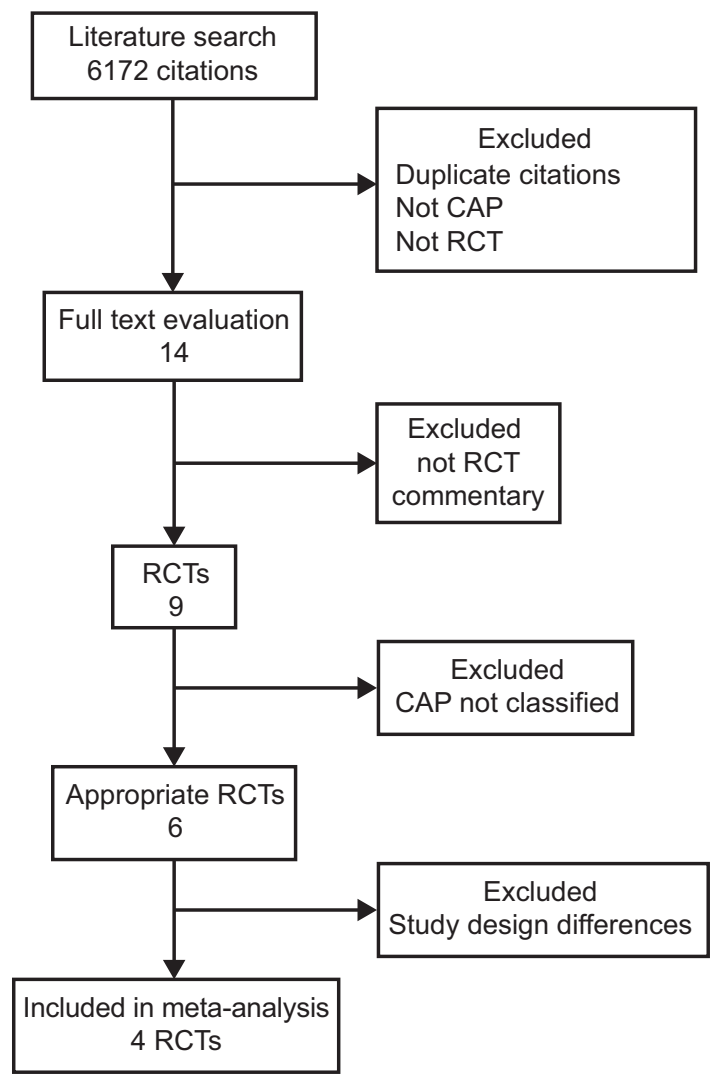

Fig. 1. Inclusion criteria flow chart. CAP $=$ community-acquired pneumonia; $\mathrm{RCT}=$ randomized controlled trial.

\section{Study Characteristics}

Table 1 presents the main characteristics of 4 trials included in this review. In total, there were 134 individuals in the intervention group and 130 individuals in the control group. Among these trials, one study 25 enrolled patients with mild-to-severe CAP, but it separately conducted a subanalysis of clinical outcomes of severe pneumonia, as defined by a CURB-65 score of $\geq 3$ or a Pneumonia Severity Index score of $\geq 4$. Corticosteroids used in these trials included hydrocortisone, prednisolone, and MPDN. The duration of corticosteroid therapy ranged from 7 to $9 \mathrm{~d}$ (in 3 studies, $7 \mathrm{~d}$; in one study, $9 \mathrm{~d}$ ).

\section{Quantitative Data Synthesis}

We summarized the pooled results of the 4 trials (Fig. 2). There was moderate heterogeneity among study results $\left(P=.14, \mathrm{I}^{2}=46 \%\right)$. Mortality of patients treated with corticosteroids was significantly lower than that of patients with placebo (Peto OR $=0.39,95 \%$ CI $0.17-0.90$ ). Table 2 shows secondary outcomes. These data suggest that therapy with corticosteroids may improve the prognosis of adult patients with severe CAP. 


\section{Corticosteroid Therapy for Severe Community-Acquired Pneumonia}

Table 1. Characteristics of the Studies Included in the Meta-Analysis

\begin{tabular}{|c|c|c|c|c|c|c|}
\hline Reference and Authors & Study Design & $\begin{array}{c}\text { Patients } \\
\text { (n; Intervention/ } \\
\text { Control) }\end{array}$ & $\begin{array}{l}\text { Mean Age } \\
\text { (y) }\end{array}$ & $\begin{array}{l}\text { Severe } \\
\text { Criterion }\end{array}$ & $\begin{array}{l}\text { Corticosteroids } \\
\text { Used }\end{array}$ & Placebo \\
\hline Confalonieri et $\mathrm{al}^{24}$ & $\mathrm{DB}, \mathrm{RCT}, \mathrm{MC}$ & $23 / 23$ & 64 & 1993 ATS & $\begin{array}{l}\text { Hydrocortisone, } \\
240 \mathrm{mg} / \mathrm{d}, 7 \mathrm{~d}\end{array}$ & Sterile normal saline \\
\hline Fernandez-Serrano et al ${ }^{21}$ & $\mathrm{DB}, \mathrm{RCT}, \mathrm{SC}$ & $23 / 22$ & 63 & Unclear & $\begin{array}{l}\text { MPDN, } 620 \mathrm{mg} \text {, } \\
9 \mathrm{~d}\end{array}$ & $\begin{array}{l}\text { Drugs with similar physical } \\
\text { appearance to corticosteroids }\end{array}$ \\
\hline Sabry and $\mathrm{Omar}^{26}$ & $\mathrm{DB}, \mathrm{RCT}, \mathrm{MC}$ & $40 / 40$ & 62 & 1998 ATS & $\begin{array}{l}\text { Hydrocortisone, } \\
300 \mathrm{mg} / \mathrm{d}, 7 \mathrm{~d}\end{array}$ & Normal saline solution \\
\hline Snijders et $\mathrm{al}^{25}$ & $\mathrm{DB}, \mathrm{RCT}, \mathrm{SC}$ & $48 / 45$ & 63 & $\begin{array}{l}\text { CURB-65 } \\
\quad(\text { score }>2)\end{array}$ & $\begin{array}{l}\text { Prednisolone, } \\
\qquad 40 \mathrm{mg} / \mathrm{d}, 7 \mathrm{~d}\end{array}$ & Unclear \\
\hline $\begin{array}{l}\text { DB = double-blind } \\
\text { RCT = randomized controlled trial } \\
\text { MC = multi-center } \\
\text { MPDN =methylprednisolone } \\
\text { SC = single center } \\
\text { ATS = American Thoracic Society } \\
\text { CURB-65 = confusion, urea nitroge }\end{array}$ & 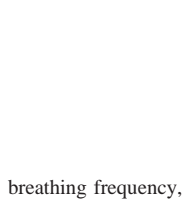 & d pressure, $\geq 65$ yea & & & & \\
\hline
\end{tabular}

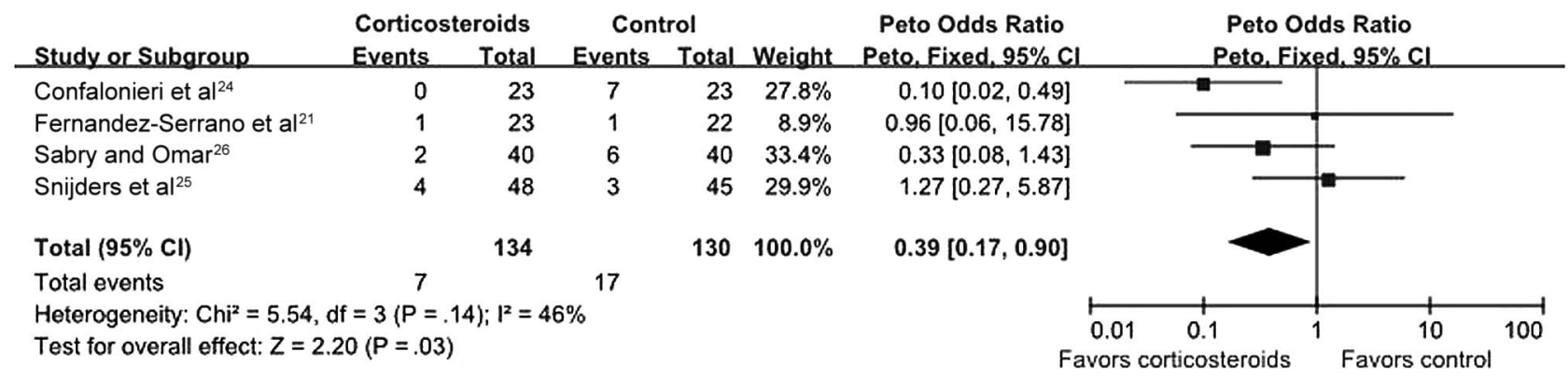

Fig. 2. Correlation between mortality and corticosteroid treatment. $\mathrm{df}=$ degrees of freedom.

Table 2. Effects of Corticosteroids vs Placebo on Different End Points of Severe CAP Studies

\begin{tabular}{|c|c|c|c|c|c|}
\hline Reference and Authors & $\begin{array}{l}\text { Length of } \\
\text { ICU Stay (d) }\end{array}$ & $\begin{array}{c}\text { Length of } \\
\text { Hospital Stay (d) }\end{array}$ & Duration of MV (d) & Days off MV & Adverse Effects \\
\hline Confalonieri et $\mathrm{al}^{24}$ & $\begin{array}{l}10(4-33)^{*} \text { vs } \\
18(3-45)^{*} \\
P=.01\end{array}$ & $\begin{array}{l}13(10-53)^{*} \text { vs } \\
21(3-72)^{*} \\
P=.03\end{array}$ & $\begin{array}{l}4(1-27)^{*} \text { vs } \\
10(2-44)^{*} \\
P=.007\end{array}$ & & $\begin{array}{l}n \text { of patients with polyneuropathy } \\
\text { of critical illness: } 0 \text { vs } 3 / 23(P=.2) \\
n \text { of patients with gastrointestinal } \\
\text { bleeding: } 1 / 23 \text { vs } 1 / 23(P=1.0)\end{array}$ \\
\hline $\begin{array}{l}\text { Fernandez-Serrano } \\
\text { et } \mathrm{al}^{21}\end{array}$ & $\begin{array}{l}6.5(5.5-9)^{*} \text { vs } \\
\quad 10.5(6.25-24.5)^{*}\end{array}$ & $\begin{array}{c}10(9-13)^{*} \text { vs } \\
11.5(9-14)^{*}\end{array}$ & 3 vs $13(7-26) *$ & & Not reported \\
\hline Sabry and $\mathrm{Omar}^{26}$ & & & & $\begin{array}{l}3.4(0.58) \dagger \mathrm{vs} \\
1.2(0.42) \dagger \\
P=.01\end{array}$ & $\begin{array}{l}\text { Ratio of patients with upper } \\
\text { gastrointestinal bleeding: } 5 \% \text { vs } 5 \% \text {; } \\
\text { patients with delayed septic shock: } \\
5 \% \text { vs } 35 \%\end{array}$ \\
\hline Snijders et $\mathrm{al}^{25}$ & & $\begin{array}{l}19.4(20.2) \dagger \mathrm{vs} \\
20.4(22.7) \dagger \\
P=.87\end{array}$ & & & Not reported \\
\hline \multicolumn{6}{|c|}{$\begin{array}{l}\text { * Data are reported as median (range). } \\
\dagger \text { Data are reported as mean (SD). } \\
\text { CAP = community-acquired pneumonia } \\
\text { MV = mechanical ventilation }\end{array}$} \\
\hline
\end{tabular}




\section{Corticosteroid Therapy for Severe Community-Acquired Pneumonia}

Table 3. Risk of Bias Summary of Included Studies

\begin{tabular}{|c|c|c|c|c|c|c|c|}
\hline Reference and Authors & $\begin{array}{c}\text { Random } \\
\text { Sequence } \\
\text { Generation }\end{array}$ & $\begin{array}{c}\text { Allocation } \\
\text { Concealment }\end{array}$ & $\begin{array}{c}\text { Blinding of } \\
\text { Participants } \\
\text { and Personnel }\end{array}$ & $\begin{array}{l}\text { Blinding of } \\
\text { Outcome } \\
\text { Assessment }\end{array}$ & $\begin{array}{l}\text { Incomplete } \\
\text { Outcome Data }\end{array}$ & $\begin{array}{l}\text { Selective } \\
\text { Reporting }\end{array}$ & $\begin{array}{l}\text { Other } \\
\text { Bias }\end{array}$ \\
\hline Confalonieri et $\mathrm{al}^{21}$ & Low risk & Low risk & Low risk & Low risk & Low risk & Low risk & Unclear risk \\
\hline Fernandez-Serrano et al ${ }^{21}$ & Low risk & Low risk & Low risk & Low risk & Low risk & Low risk & Low risk \\
\hline Sabry and $\mathrm{Omar}^{26}$ & Low risk & Low risk & Low risk & Low risk & Low risk & Low risk & Unclear risk \\
\hline Snijders et al ${ }^{25}$ & Low risk & Low risk & Low risk & Low risk & Low risk & Low risk & Low risk \\
\hline
\end{tabular}

\section{Sensitivity Analysis and Publication Bias}

A sensitivity analysis was carried out by the sequential dropping of each study. Significant differences were observed for 2 studies, resulting in no significant mortality reduction. Although the study by Confalonieri et $\mathrm{al}^{24}$ had a heavy weight of $27.8 \%$, when excluded from the data, the pooled result showed no effect of corticosteroids in patients with severe CAP (Peto OR $=0.66,95 \%$ CI 0.25 1.77), and heterogeneity was considerably reduced $\left(\mathrm{I}^{2}=0 \%\right)$. Similarly, when the study by Sabry and $\mathrm{Omar}^{26}$ was dropped, the results also changed significantly, with common Peto ORs of 0.42 (95\% CI 0.15-1.18; weight $=33.4 \%$ ).

Publication bias was not assessed because of the limited number $(<10)$ of studies included in this analysis.

\section{Discussion}

This is the first meta-analysis of RCTs to evaluate the outcome of corticosteroids as adjunctive therapy in adult patients with severe CAP. Unlike the systematic review by Salluh et al,22 all eligible trials we included were doubleblinded RCTs with high quality. Table 3 shows the risk of bias varying across trials. Double-blinded RCTs were assigned to a low risk of bias. Our analysis suggests that corticosteroids may reduce overall mortality and improve the outcomes of patients with severe CAP. Recently, Nie et $\mathrm{a}^{23}$ performed a meta-analysis of RCTs to assess the benefits and risks of corticosteroids in the treatment of CAP in adults. They showed that a benefit was not found for corticosteroid treatment of patients with CAP, but analyses restricted to severe CAP patients or prolonged corticosteroid treatment showed a survival benefit. A retrospective cohort study conducted by Garcia-Vidal et $a^{28}$ pointed out that mortality decreased in the patients with severe CAP who received steroids along with antibiotic treatment. Mikami et al ${ }^{27}$ demonstrated that a short course of low-dose corticosteroids administered to patients with moderate-to-severe CAP promoted the resolution of clinical symptoms and reduced the duration of intravenous antibiotic therapy. In a retrospective study about the efficacy of MPDN therapy in patients with severe pneumonia, Kiyokawa and Kawai ${ }^{31}$ suggested that the administration of steroids in the early stage after the onset of pneumonia could increase the average cure rate.

However, the findings of the present study must be viewed in the context of potential limitations. First, the sensitivity analysis revealed the instability of pooled estimates due to the limited number of studies included, which reflected substantial heterogeneity among those studies. In this study, the instability was associated with differences in corticosteroid administration, antibiotic therapy, characteristics of population, definition of severe CAP, and study design. Two trials ${ }^{24,26}$ used hydrocortisone, and the other two used prednisolone ${ }^{25}$ and MPDN. ${ }^{21}$ All studies used long-course treatment, $7 \mathrm{~d}$ in 3 trials $^{24-26}$ and $9 \mathrm{~d}$ in one trial. ${ }^{21}$ In addition, the choice and dose of antibiotics may influence results. Only one study overcame this problem by administering the same antibiotics (ceftriaxone plus levofloxacin). ${ }^{21}$ Second, this study lacked the power to test publication bias because of the limited number $(<10)$ of trials included. In the study by Confalonieri et al, ${ }^{24} 7 \mathrm{pa}$ tients died in the control group, but none died in the intervention group, which may generate high publication bias. Importantly, the small sample size, a common problem in 4 studies, may have biased their results. Moreover, this meta-analysis lacked pooled effect to detect potentially significant harmful effects because of a relatively small number of included trials. Only 2 trials reported adverse effects, including gastrointestinal bleeding, polyneuropathy of critical illness, and delayed septic shock. ${ }^{24,26}$ Snijders et al ${ }^{25}$ did not report adverse effects in patients with a CURB-65 score of $>2$. Finally, various types, dosages, and durations of corticosteroids were used in the 4 trials. In addition, the diagnosis criteria of severe pneumonia were not exactly the same in these trials. So far, there are only a few reports regarding steroid dosage and duration in pneumonia patients. Nie et $\mathrm{al}^{23}$ found that prolonged corticosteroid treatment for severe CAP provided a survival benefit. Mikami et al ${ }^{27}$ reported that administration of short-course and low-dose corticosteroids promoted improvement in major symptoms and shortened the duration of antibiotic treatment. Kiyokawa and Kawai ${ }^{31}$ found that the total dose of steroids given within $7 \mathrm{~d}$ was lower in cured cases $(774 \pm 749 \mathrm{mg})$ than in non-cured cases $(1,190 \pm 768 \mathrm{mg})(P<.05)$. This indicated that there was 


\section{Corticosteroid Therapy for Severe Community-Acquired Pneumonia}

an association between corticosteroid dose and severity of pneumonia. Given the critical flaws outlined above, the benefit of corticosteroid treatment in adult patients with severe CAP should be viewed with caution. Therefore, large-scale and well-designed RCTs are urgently needed. In future studies, the drug used, duration of therapy, dose of corticosteroids, and adverse effects also should be given more attention.

\section{Conclusion}

On the basis of the current limited evidence, we suggest that, although corticosteroid therapy may reduce mortality and improve the prognosis of adult patients with severe CAP, the results should be interpreted with caution due to the instability of pooled estimates. Reliable treatment recommendations will be raised only when large sufficiently powered multi-center RCTs are conducted.

\section{REFERENCES}

1. Shah SS, Ratner AJ. Trends in invasive pneumococcal disease-associated hospitalizations. Clin Infect Dis 2006;42(1):e1-e5.

2. Robinson KA, Baughman W, Rothrock G, Barrett NL, Pass M, Lexau C, et al. Epidemiology of invasive Streptococcus pneumoniae infections in the United States, 1995-1998: opportunities for prevention in the conjugate vaccine era. JAMA 2001;285(13):1729-1735.

3. File TM Jr, Marrie TJ. Burden of community-acquired pneumonia in North American adults. Postgrad Med 2010;122(2):130-141.

4. Rodriguez A, Mendia A, Sirvent JM, Barcenilla F, de la TorrePrados MV, Sole-Violan J, et al. Combination antibiotic therapy improves survival in patients with community-acquired pneumonia and shock. Crit Care Med 2007;35(6):1493-1498.

5. Alvarez-Lerma F, Torres A. Severe community-acquired pneumonia. Curr Opin Crit Care 2004;10(5):369-374.

6. Moret I, Lorenzo MJ, Sarria B, Cases E, Morcillo E, Perpina M, et al. Increased lung neutrophil apoptosis and inflammation resolution in nonresponding pneumonia. Eur Respir J 2011;38(5):11581164.

7. Endeman H, Meijvis SC, Rijkers GT, van Velzen-Blad H, van Moorsel $\mathrm{CH}$, Grutters JC, et al. Systemic cytokine response in patients with community-acquired pneumonia. Eur Respir J 2011;37(6):14311438.

8. Antunes G, Evans SA, Lordan JL, Frew AJ. Systemic cytokine levels in community-acquired pneumonia and their association with disease severity. Eur Respir J 2002;20(4):990-995.

9. Kellum JA, Kong L, Fink MP, Weissfeld LA, Yealy DM, Pinsky MR, et al. Understanding the inflammatory cytokine response in pneumonia and sepsis: results of the Genetic and Inflammatory Markers of Sepsis (GenIMS) Study. Arch Intern Med 2007;167(15):1655-1663.

10. Menendez R, Cavalcanti M, Reyes S, Mensa J, Martinez R, Marcos MA, et al. Markers of treatment failure in hospitalised community acquired pneumonia. Thorax 2008;63(5):447-452.

11. Fernandez-Serrano S, Dorca J, Coromines M, Carratala J, Gudiol F, Manresa F. Molecular inflammatory responses measured in blood of patients with severe community-acquired pneumonia. Clin Diagn Lab Immunol 2003;10(5):813-820.

12. Monton C, Ewig S, Torres A, El-Ebiary M, Filella X, RanoA, et al. Role of glucocorticoids on inflammatory response in nonimmunosuppressed patients with pneumonia: a pilot study. Eur Respir J 1999;14(1):218-220.
13. Marik PE, Pastores SM, Annane D, Meduri GU, Sprung CL, Arlt W, et al. Recommendations for the diagnosis and management of corticosteroid insufficiency in critically ill adult patients: consensus statements from an international task force by the American College of Critical Care Medicine. Crit Care Med 2008;36(6):1937-1949.

14. Salluh JI, Verdeal JC, Mello GW, Araujo LV, Martins GA, de Sousa Santino M, et al. Cortisol levels in patients with severe communityacquired pneumonia. Intensive Care Med 2006;32(4):595-598.

15. Salluh JI, Bozza FA, Soares M, Verdeal JC, Castro-Faria-Neto HC, Lapa E Silva JR, et al. Adrenal response in severe communityacquired pneumonia: impact on outcomes and disease severity. Chest 2008;134(5):947-954.

16. Meduri GU, Kanangat S, Bronze M, Patterson DR, Meduri CU, Pak $\mathrm{C}$, et al. Effects of methylprednisolone on intracellular bacterial growth. Clin Diagn Lab Immunol 2001;8(6):1156-1163.

17. Salluh JI, Soares M, Coelho LM, Bozza FA, Verdeal JC, CastroFaria-Neto HC, et al. Impact of systemic corticosteroids on the clinical course and outcomes of patients with severe community-acquired pneumonia: a cohort study. J Crit Care 2011;26(2):193-200.

18. Polverino E, Cilloniz C, Dambrava P, Gabarrus A, Ferrer M, Agusti $\mathrm{C}$, et al. Systemic corticosteroids for community-acquired pneumonia: reasons for use and lack of benefit on outcome. Respirology 2013;18(2):263-271.

19. Chon GR, Lim C-M, Koh Y, Hong S-B. Analysis of systemic corticosteroid usage and survival in patients requiring mechanical ventilation for severe community-acquired pneumonia. J Infect Chemother 2011;17(4):449-455.

20. Marik P, Kraus P, Sribante J, Havlik I, Lipman J, Johnson DW. Hydrocortisone and tumor necrosis factor in severe community-acquired pneumonia. A randomized controlled study. Chest 1993; 104(2):389-392.

21. Fernandez-Serrano S, Dorca J, Garcia-Vidal C, Fernandez-Sabe N, Carratala J, Fernandez-Aguera A, et al. Effect of corticosteroids on the clinical course of community-acquired pneumonia: a randomized controlled trial. Crit Care 2011;15(2):R96.

22. Salluh JIF, Povoa P, Soares M, Castro-Faria-Neto HC, Bozza FA, Bozza PT. The role of corticosteroids in severe community-acquired pneumonia: a systematic review. Crit Care 2008;12(3):R76.

23. Nie W, Zhang Y, Cheng J, Xiu Q. Corticosteroids in the treatment of community-acquired pneumonia in adults: a meta-analysis. PLoS ONE 2012;7(10):e47926.

24. Confalonieri M, Urbino R, Potena A, Piattella M, Parigi P, Puccio G, et al. Hydrocortisone infusion for severe community-acquired pneumonia: a preliminary randomized study. Am J Respir Crit Care Med 2005;171(3):242-248.

25. Snijders D, Daniels JMA, de Graaff CS, van der Werf TS, Boersma WG. Efficacy of corticosteroids in community-acquired pneumonia: a randomized double-blinded clinical trial. Am J Respir Crit Care Med 2010;181(9):975-982.

26. Sabry NA, Omar EE-D. Corticosteroids and ICU course of community acquired pneumonia in Egyptian settings. Pharmacol Pharm 2011;2(2):73-81.

27. Mikami K, Suzuki M, Kitagawa H, Kawakami M, Hirota N, Yamaguchi $\mathrm{H}$, et al. Efficacy of corticosteroids in the treatment of community-acquired pneumonia requiring hospitalization. Lung 2007; 185(5):249-255.

28. Garcia-Vidal C, Calbo E, Pascual V, Ferrer C, Quintana S, Garau J. Effects of systemic steroids in patients with severe community-acquired pneumonia. Eur Respir J 2007;30(5):951-956.

29. Bradburn MJ, Deeks JJ, Berlin JA, Russell Localio A. Much ado about nothing: a comparison of the performance of meta-analytical methods with rare events. Stat Med 2007;26(1):53-77. 


\section{Corticosteroid Therapy for Severe Community-Acquired Pneumonia}

30. Sterne JA, Egger M, Smith GD. Systematic reviews in health care: investigating and dealing with publication and other biases in metaanalysis. BMJ 2001;323(7304):101-105.

31. Kiyokawa K, Kawai S. Efficacy of steroid therapy on adult patients with severe pneumonia. J Infect Chemother 2010;16(4):266-271.

32. Salluh JI, Soares M, Povoa P. Corticosteroids in severe communityacquired pneumonia: the path we choose depends on where we want to get. Crit Care 2011;15(2):137.

33. Wagner HN Jr, Bennett IL Jr, Lasagna L, Cluff LE, Rosenthal MB, Mirick GS. The effect of hydrocortisone upon the course of pneu- mococcal pneumonia treated with penicillin. Bull Johns Hopkins Hosp 1956;98(3):197-215.

34. McHardy VU, Schonell ME. Ampicillin dosage and use of prednisolone in treatment of pneumonia: co-operative controlled trial. $\mathrm{Br}$ Med J 1972;4(5840):569-573.

35. Meijvis SCA, Hardeman H, Remmelts HHF, Heijligenberg R, Rijkers GT, van Velzen-Blad H, et al. Dexamethasone and length of hospital stay in patients with community-acquired pneumonia: a randomised, double-blind, placebo-controlled trial. Lancet 2011; 377(9782):2023-2030. 